\title{
On Embodiment of Predicative Metaphor: A Case of English Body-action Verbs
}

\author{
Mingjie Huo \\ College of International Studies, Southwest University, Chongqing, China; \\ School of Foreign Studies, Guangzhou University, Guangzhou, China \\ Jiaxuan Chen \\ School of Foreign Studies, Guangzhou University, Guangzhou, China
}

\begin{abstract}
This paper presents an analysis of embodiment of predicative metaphor which is an important topic in cognitive linguistic study. Previous researches are mainly about the identification, classification and construal of predicative metaphor, while its cognitive motivation has not been discussed. Based on the conceptual metaphor theory and embodied philosophy, the cognitive motivation of the metaphorical usage of English body-action verbs is discussed. It is concluded that the metaphorical usage of English body-action verbs arises from the embodied experience. Concepts related to human body are preferred to be the source domain of the cross-domain mapping used to understand other concepts. The metaphorical usage of English body-action verbs is created through human body metaphor.
\end{abstract}

Index Terms - predicative metaphor, body-action verbs, motivation, embodied Philosophy

\section{INTRODUCTION}

Metaphor is "a matter of thought and action and only derivatively a matter of language" (Lakoff \& Johnson, 1980, p.153). Most of the researches on metaphor within the scope of cognitive science focus on nominal metaphors. "Using isolated, nominal, clause-length metaphors as typical exemplars in theory-building may also be misleading" (Cameron, 1999, p. 16). Verb plays a significant role in every language, and its metaphorical usage is also of great importance to metaphor study. The completeness of research on metaphor cannot be achieved without studying the metaphorical usage of other parts of speech, for example, that of verb. Relevant literature on the metaphorical usage of verbs has touched upon the identification, classification, construal of predicative metaphors (Su, 2017) and the metaphorical usage of certain subclass of verbs, for instance, sensory verbs. However, these aspects are primarily concerned with the linguistic manifestations of predicative metaphors. The cognitive motivation of the metaphorical usage of verbs, especially subclass of verbs, has not yet been explored. Body-action verbs are verbs indicating mechanical actions made by people using certain parts of their bodies (Wang, Li, Wu \& Zhang, 2019). The conventionalized metaphorical usage of such high-frequency words is indispensable to conceptual metaphor study and the cognitive motivation of such usage is a necessity.

The present paper intends to analyze the cognitive motivation of the metaphorical usage of English body-action verbs under the conceptual metaphor theory and embodied philosophy hoping to make contributions to a better understanding of English body-action verbs as well as further the study on predicative metaphor. The paper begins by presenting previous researches on predicative metaphor before introducing the theoretical bases, namely Conceptual Metaphor Theory and the Embodied Philosophy. It then turns to discussing metaphorical usage of English body-action verbs. And the cognitive motivation of the metaphorical usage of English body-action verbs is explored.

\section{Previous Researches on Predicative Metaphor}

Literature review on predicative metaphor is presented in this part, and previous studies on the metaphorical usage of verbs are reviewed. And limitations of the previous studies are pointed out. Then an explanation of English body-action verbs is given.

Researches on the metaphorical usage of verbs have been increasing. They focused on such different aspects as identification, classification and construal of predicative metaphors (Su, 2017). Different scholars held different views to the identification of metaphorical usage of verbs. Kittay (1987) argued that identifying the unit of discourse that constitutes a metaphor is the precondition for the identification of metaphor, which applies to predicative metaphor as well. Goatly (1997, p. 79) thought that unconventional reference and/or semantic contradiction exerts a considerable influence on the successful identification of a metaphor. Torreano, Cacciari and Glucksberg (2005) claimed that the level of abstraction of a verb serves well as a cue to metaphorical usage of verbs and through an experiment they showed that when a verb is interpreted at a higher level of abstraction, it is more metaphorical. Ge and Zhao (2010) pointed out different ways of recognition according to their classification of predicative metaphors. Semantic conflicts 
resulting from collocation of non-phrasal action verbs and nouns which do not belong to the same category can be used as a cue. And the recognition of metaphorical usage of phrasal verbs can be achieved by examining the collocation of verbs and particles. Zhang and Zhu (2011) added that to see whether a verb is used metaphorically, the specific context should be considered. It is proposed that the identification be done by judging the authenticity of the reference of the collocation of verbs and nouns under common sense.

A few researchers made attempts to classify the metaphorical usage of verbs in their studies. Yang and Huang (2000) sorted predicative metaphor mainly into two types: metaphorical usage of denominal verbs and metaphorical usage of words which are verbs originally. Peng (2010) held that there are three types of metaphorical mapping of verbs: from specific domain to abstract domain, from one specific domain to another specific domain and from specific domain to another specific domain which is of abstract nature. Ge and Zhao (2010) analyzed their metaphorical usage of non-phrasal action verbs and phrasal verbs. Zhang and Zhu (2011) divided predicative metaphors into three types: metaphor arose from the semantic conflicts between subject and verb, between verb and object and between verb and both subject and object according to the ways of identification mentioned above.

The construal of metaphorical usage of verbs was another focus of previous studies. Goatly (1997, pp. 82-83) stated that the construal of predicative metaphor involves a process called "vehicle-construction", arguing that "metaphorically used verbs can indirectly evoke imagery but only by being hooked up to their conventional colligates". For example, when referring to the verb "kick", the image of a foot may come into one's mind. By applying the Dynamic Construal Approach put forward by Croft and Cruise (2004, p. 141), Zhang and Zhu (2011) presented a detailed analysis of the construal of metaphorical usage of verbs. From their perspective, construing predicative metaphor includes three stages, namely, perceiving the existence of a metaphor, finding out related concepts in the source domain, and connecting the target domain with the source domain. Some scholars viewed that embodied simulation contributes to the comprehension of predicative metaphor. Wilson and Gibbs (2007), conducting two experiments, revealed that real or imagined body actions help to promote the construal of metaphorical usage of verbs representing those actions.

Some researchers concentrated their studies on the metaphorical usage of certain subclass of verbs. Gao and Qin (2009) took Chinese and English verbs in the category of food as research objects, and comparatively analyzed the similarities and differences between their conceptual metaphor mapping. Peng (2010) explored the embodiment of structural metaphor, orientational metaphor and ontological metaphor in human body verbs and pointed out that metaphor plays a crucial role in the extension of the meaning of human body verbs. Peng and Lv (2015), from the perspectives of metaphorical image schema and metaphorical cognitive model, studied the metaphorical mechanism and cognitive operation of Russian verbs with the meaning of thought.

Previous studies on the metaphorical usage of verbs have, to some degree, enriched research on predicative metaphor and enhanced our understanding of this subject. However, the cognitive motivation of the metaphorical usage of verbs, especially that of subclass of verbs, has not been fully explored in the studies. It remains to be analyzed whether the cognitive, psychological and linguistic causes of metaphor can be applied to explain the motivation of predicative metaphor especially that of the metaphorical usage of body-action verbs. On this account, the present work is carried out with an aim to investigate the cognitive motivation of English body-action verbs.

Body-action verbs refer to verbs indicating mechanical actions made by people using certain parts of their bodies (Wang, Li, Wu \& Zhang, 2019). Mostly monosyllabic and expressing concrete actions, almost all these verbs are native words in English and are frequently used in everyday speech and writing. They are so frequently used that their metaphorical usage is not easy to notice. They become conventionalized metaphors. "Those that are most alive and most deeply entrenched, efficient and powerful are those that are so automatic as to be unconscious and effortless" (Lakoff \& Turner, 1989, p. 129). This means conventionalized metaphor, to some extent, can better reflect the essence of our cognition. This is also one of the reasons why body-action verbs are chosen as the research objects of the present study.

Human body can be generally divided into four parts: head (face included), trunk, arms (hands included) and legs (feet included). Since most body-action verbs used in daily life relate to hands or feet, the current study plans to divide the research objects into three categories: verbs related to hands, verbs related to feet and verbs related to other parts of human body. To ensure the reliability of the choice of the research objects, verbs used for the present research are selected from Oxford Collocations Dictionary (Second Edition). Only verbs that are common and have metaphorical usage are chosen. Body-actions verbs appropriate for further studies are as follows.

\begin{tabular}{|l|l|}
\hline \multicolumn{1}{|c|}{ Categories } & \multicolumn{1}{c|}{ Specific Body-Action Verbs } \\
\hline Verbs related to hands & $\begin{array}{l}\text { beat, bring, catch, carry, clap, grab, grasp, hit, hold, knock, lift, pick, point, pour, } \\
\text { pull, push, raise, reach, seize, shake, sweep, take, tear, throw, tie, touch, write }\end{array}$ \\
\hline Verbs related to feet & jump, kick, leap, run, skip, stamp, stand, step, walk \\
\hline $\begin{array}{l}\text { Verbs related to other parts of } \\
\text { human body }\end{array}$ & bite, chew, climb, lean, lie, nod, stretch, strike, sit, swallow \\
\hline
\end{tabular}

\section{THEORETICAL BASES}

Conceptual metaphor theory and the embodied philosophy serve as the bases of the following analysis. They will be 
applied to discuss the metaphorical usage of English body-action verbs and their cognitive motivation.

\section{A. Conceptual Metaphor Theory}

Lakoff \& Johnson (1980, p. 4) stated that "our ordinary conceptual system is metaphorical in nature". Metaphor is not just a rhetorical device, but more of a way of thinking. It is "understanding and experiencing one kind of thing in terms of another" (Lakoff \& Johnson, 1980, p. 5), metaphorical concepts are classified mainly into three types, namely, structural metaphors, orientational metaphors and ontological metaphors.

Metaphorical concept like "TIME IS MONEY" is an example of structural metaphor, in which "one concept is metaphorically structured in terms of another" (Lakoff \& Johnson, 1980, p. 14). In structural metaphors, words or expressions employed in one concept which is comparatively concrete and familiar to us are used to conceptualize the other concept that is rather abstract and complex. For instance, in the "TIME IS MONEY" metaphor, words that are normally used to describe money are applied to express time, such as "waste time", "spend time", "save time" and so on.

Orientational metaphors, as the name indicates, are metaphorical concepts built with respect to spatial orientations such as up and down, in and out. Ingrained in our physical and cultural experience, orientational metaphors give rise to a series of normal expressions in our daily life. For example, the expression "I'm feeling up today" (which means "I'm feeling happy today") is acceptable because there exists a metaphorical concept — "HAPPY IS UP" in our experience (Lakoff \& Johnson, 1980, p. 14).

Ontological metaphors can be further divided into entity and substance metaphors and container metaphors. Entity and substance metaphors arise from our experience of physical objects and substances. As the term suggests, they are metaphorical concepts structured in terms of entities or substances. Regarding abstract concepts such as emotions and events as concrete entities or substances enables people to understand it better. Taking "He broke down" (which means "He mentally collapsed") as an example, an ontological metaphor "THE MIND IS A MACHINE" is involved.

\section{B. The Embodied Philosophy}

Different from the traditional western philosophy which mainly concerns with the divergence of perceptualism (includes empiricism) and rationalism, the embodied philosophy (Lakoff \& Johnson. 1999) advocates the interaction between human beings and the objective world and insists the embodied research on human's mind and cognition. It is regarded as the second-generation cognitive science (Wang, 2002). The conceptual metaphor theory, as a vital part of the cognitive science, is based on the embodied philosophy. Thus, to explore the cognitive motivation of the English body-action verbs metaphor, it is necessary to elaborate the embodied philosophy. The embodied philosophy consists of three basic principles: the unconsciousness of cognition, the embodiment of mind and the metaphorical nature of thought.

The unconsciousness of cognition indicates that "most of our thought is unconscious" (Lakoff \& Johnson, 1999, p. 20). Our thinking process is quite quick and complicated and involves lots of cognitive processes and neural processes. Therefore, it is impossible for us to perceive and control it. In this sense, those conceptual systems, meaning, inference and language in our cognition are mostly unconscious (Lakoff \& Johnson, 1999, p. 21). The embodiment of mind holds that "concepts and reason are embodied" (Lakoff \& Johnson, 1999, p. 28). It is argued that human categories, concepts and reason are neither naturally earned, nor are they direct reflections of an external reality. Instead, they are closely related to our experience with the objective world, and form through unconscious cognitive processing. In other words, human brains and bodies play a vital part in the formation of concepts (Lakoff \& Johnson, 1999, pp. 26-31; Wang, 2011, pp. 19-20). The metaphorical nature of thought reveals that human thought and language are essentially metaphorical. As mentioned above, human thought is by no means the direct reflection of the external, objective world. Therefore, it is inevitable that we understand and comprehend one concept with the help of another. Common subjective experience is conceptualized through cross-domain mappings, with our sensorimotor experience serving as the source domain. Metaphor makes it possible for people to think about subjective experience and judgment. It is a cognitive approach ingrained in human mind (Lakoff \& Johnson, 1999, pp. 60-62; Wang, 2011, p, 21).

The conceptual metaphor theory and the embodied philosophy serve as the theoretical bases of the research for there are certain links among the theories and the present study. For one thing, conceptual metaphor theory concisely defines and clearly explains what a metaphorical concept is, making it possible for the present work to recognize the metaphorical concepts residing in English body-action verbs and to conduct a further study on them. The metaphorical usage of English body-action verbs belongs to ontological metaphor. Body-action verbs are collocated with physical entities and substance, for example, "kick a football". However, when used metaphorically, they are applied to more abstract and subjective concepts. For instance, when used metaphorically, "kick" may be collocated with "a bad habit". For another thing, this thesis aims at exploring the motivation of the metaphorical usage of English body-action verbs from a cognitive point of view. English body-action verbs metaphor, as a specific kind of conceptual metaphor, is also based on the embodied philosophy. Accordingly, discussion of the cognitive motivation of the metaphorical usage of English body-action verbs is carried out under the guidance of the three principles of the embodied philosophy.

\section{Metaphorical Usage of English Body-ACtion VerbS}


In this part, a study on the metaphorical usage of English body-action verbs is carried out. Example sentences of the metaphorical usage of body-action verbs are chosen from Oxford Advanced Learner's English-Chinese Dictionary and are explored. For each category of body-action verbs, several examples that can well represent the common features of the metaphorical usage of English body-action verbs are analyzed.

\section{A. Metaphorical Usage of Verbs Related to Hands}

In terms of the metaphorical usage of verbs related to hands, examples of "catch", "hit" and "knock" are selected.

(1) I caught a look of surprise on her face.

"Catch" originally means holding something concrete and tangible in one's hand (Hornby, 2009, p.300), while here the object of it is "a look of surprise". Taking one's facial expression as a physical object, it is obviously an ontological metaphor. The verb "catch" in this sentence can no longer be literally interpreted as "take hold of something" since "a look of surprise", being rather abstract, cannot be held in one's hand. Instead, it should be metaphorically interpreted as "notice".

(2) The tax increases will certainly hit the poor.

The literal meaning of "hit" is to hurt somebody or something with one's hand or with an object in a quick and forceful way (Hornby, 2009. p. 969). While in the given example, the subject of "hit" is "the tax increases". The increase of tax, which is an event, is viewed as an entity. The event may not cause physical damage to the poor but will certainly have a bad influence on them. The adverse effect of tax increases on the poor is like the damage that an entity or one's hand can cause to people. Therefore, the verb "hit" in this example should be metaphorically understood as "have a bad effect on".

(3) The criticism had knocked her self-esteem.

The original meaning of "knock" is to hit some material object like a door, a window or a desk to arouse attention (Hornby, 2009, p. 1118). In the above example, "her self-esteem”, which refers to a person's subjective feeling, is unconventionally collocated with "knock". Knocking material objects involves physical contact, while a person's self-esteem, being rather abstract and intangible, cannot be physically hit. Taking the impact of "the criticism" can have on a person's "self-esteem" into consideration, "knock" here should be metaphorically interpreted as "to hurt or damage".

\section{B. Metaphorical Usage of Verbs Related to Feet}

As for the metaphorical usage of verbs related to feet, examples of "jump", "stand" and "run" are chosen.

(4) Sales jumped by $60 \%$ last year.

Literally, "jump" means "to move quickly off the ground or away from a surface by pushing yourself with your legs and feet" (Hornby, 2009, p. 1100). In the above example, "sales", which is the subject of "jump", are inanimate things. Here, the sudden increase of sales is metaphorically regarded as people's action of moving quickly off the ground, since the two concepts share a similarity. Regarding this, it can be inferred that the metaphorical meaning of "jump" is "to increase suddenly".

(5) Modern plastics can stand very high and very low temperatures.

It is generally accepted that the verb "stand" refers to a person being in a vertical position with his or her feet or something put in a vertical position somewhere (Hornby, 2009, p. 1961). However, in this example, "temperatures" serve as the object of "stand". "Temperatures" are intangible, so it is impossible for "the modern plastics" to be on it vertically. Therefore, the given sentence can only make sense through metaphorical interpretation. If modern plastics can "stand" up in very high and very low temperatures, it does not "fall". Or to be more exact, it does not "melt". Modern plastics remain undamaged in very high and very low temperatures. Thus, the verb "stand" should be metaphorically explained as "can resist something and remain in good condition".

(6) A shiver ran down my spine.

Literally, "run" describes one's body movement using his legs at a speed faster than walking (Hornby, 2009, p. 1749). When it comes to the verb "run", the image of legs or feet may naturally emerge in one's mind. In the above sentence, the subject of "run" is "a shiver", indicating one's subjective experience. Therefore, it can be inferred that "run" metaphorically means "to make somebody feel something".

\section{Metaphorical Usage of Verbs Related to Other Parts of Human Body}

As for verbs related to other parts of human body, examples of the metaphorical usage of "strike", "sit" and "chew" are presented here.

(7) An awful thought has just struck me.

The verb "strike" originally refers to hitting somebody or something with one's body or with other entities. Nevertheless, the subject of it in the above sentence - "an awful thought" is nonphysical and quite abstract. Obviously, it is an ontological metaphor which views "thought" as a physical object. Striking somebody with body or a weapon involves contact, likewise, striking somebody with a thought may get the person to know the thought. It is then clear that "strike" here means "to come into one's mind suddenly" (Hornby, 2009, p. 2000).

(8) Candidates will sit the examinations in June.

The verb "sit" is commonly understood as "to rest one's weight on one's bottom with his or her back vertical, for 
example, on/in a chair" (Hornby, 2009, p. 1875). But in the above example, "sit" is collocated with "examination". "Examination" is not an entity that can be used for people to rest on but an event. Therefore, metaphorical interpretation should be adopted. It is surely impossible for people to "sit" on the examination, while they can sit in the classroom where an examination is held. In this way, it is easy to conclude that the verb "sit" in this sentence conveys a metaphorical meaning, that is, "to take part in an exam".

(9) In a few years he had climbed to the top of his profession.

The literal meaning of "climb" is to move up towards the top of something, like a mountain, a tree or a wall (Hornby, 2009 , p. 358). In the example above, "the top of his profession", which is the object of "climb", is an abstract concept. Apparently, "climb" here no longer refers to changes in the relative position. Instead, it metaphorically means "the promotion in one's social rank".

\section{Motivation of Metaphorical Usage of English Body-action VerbS}

Most verbs concerning certain parts of human body have metaphorical usage. In this part, further discussion on the cognitive motivation of the metaphorical usage of English body-action verbs is conducted according to the three principles of embodied philosophy.

\section{A. Concepts Related to Human Body as Preferential Source Domain}

Human cognition is limited not only by time and space, but also by the structure of our sensory organs. To explore the outside world or things and concepts beyond our body, it is inevitable that we experience those unfamiliar and abstract concepts in terms of the knowledge and concepts that are already known to us (Su, 2000). First and foremost, we encounter our body and learn or acquire concepts related to human. As the most familiar concepts to us, they are most commonly used to understand those abstract and complex concepts and ideas. Specifically, in the present study, concrete body-action verbs are applied to refer to events like "the tax increases" and "examinations", subjective experiences like "an awful thought", "a shiver", "one's self-esteem" and "a look of surprise", nonphysical things like "sales", "the top of one's profession" and "very high and very low temperatures".

As the unconsciousness of mind indicates, human thoughts are mostly unconscious. According to Lakoff and Turner (1989, p. 167), human naturally forms certain orders of the beings in the world. They called such orders "the Great Chain of Beings". It is a cultural model ingrained in our cognition that somehow affects our understanding of ourselves, the world around us and the language we use. People unconsciously establish in their mind the great chain hierarchically in the order of human, animal, plant, inanimate object. And concepts in our cognition are also arranged in such orders ( $\mathrm{Hu} \& \mathrm{Xu}, 2020)$.

"A look of surprise", "the tax increases", "sales", "very high and very low temperatures", "an awful thought", "examination", "a shiver", "one's self-esteem" and "the top of one's profession" are all concepts related to human life. To gain a better understanding of these relatively abstract concepts that belong to the field of inanimate object, concepts from higher levels may be borrowed. Since they are closely related to human life, words and expressions from the highest level of the great chain - human, are preferable to be the source domain of metaphorical mapping. In this case, they are metaphorically collocated with body-action verbs in the semantic category of human, making them easier and more vivid to understand.

In brief, concepts related to human, ranking in the highest level of the unconscious great chain in our mind, are preferentially selected as the source domain to explore concepts of the lower order which are relatively complex and abstract.

\section{B. Human's Body Experience as Cognitive Basis}

In the case of the metaphorical usage of English body-action verbs, people's experiences of their own body play a vital role. It is always the case that people understand and experience the outside world based on experiences of their own body, since human cognition, at the very outset, starts from experiences of their own body and the spatial orientation. Based on these, our cognition develops from near to far, from concrete to abstract, from the body and the spatial orientation to other semantic domains (Wang, 2005). Man knows himself first, thus forms an understanding of his own and gains experiences of his own body, by which he explores and understands the outside world. As Protagoras, a well-known Greek Philosopher has pointed out, "man is the measure of all things".

Referring to the example discussed in the previous part, "sales jumped by $60 \%$ last year", in which the dramatic increase of sales is metaphorically connected with people's body action of moving quickly off the ground. Perceiving their own body experience first, people employ the verb "jump" to describe this kind of action. Then, as their cognitive domain expands to business activities, there is a need to refer to concepts, activities, events, etc. in this domain. To be more specific, in this example, there is a need to refer to the rapid increase of sales. And the rapid increase of sales is quite like people's action of jumping off the ground quickly. With such a cognitive basis from our own body, "jump" is therefore metaphorically applied to depict this event. Likewise, as the promotion in one's social rank shares a similarity to human's body experience of moving up towards the top of a mountain or a tree, "climb" is metaphorically used to describe the improvement of one's social status.

Lakoff and Johnson (1980, p. 25) mentioned that, "our experience with physical objects (especially our own bodies) 
provides the basis for an extraordinarily wide variety of ontological metaphors". This is also consistent with "the embodiment of mind" held by the embodied philosophy. In conclusion, human's experiences with their own body serve as vital cognitive basis for the metaphorical usage of English body-action verbs.

\section{Human Body Metaphor as Cognitive Approach}

As revealed by the metaphorical nature of thought, human thought and language are metaphorical. Human body metaphor, embodied by the metaphorical usage of English body-action verbs in this case, is of great significance to human cognition. Metaphor, as an indispensable cognitive approach in human life, is one of the fundamental ways people understand the world and is primary in human thought. Human naturally forms subjective judgments and experiences about abstract things and concepts such as importance and desire. Since these subjective judgments and experiences are wide-ranging and quite rich, it is inevitable that we understand them through cross-domain conceptual mapping. That is, we conceptualize them or reason about them by experiences of other domains, mainly sensorimotor domains (Lakoff \& Johnson, 1999, p. 50). As in the example given above, "an awful thought has just struck me", our subjective experience of having an awful idea is conceptualized in terms of the sensorimotor experience of being struck by an object. And in the example "I caught a look of surprise on her face", our subjective experience of noticing one's emotional feeling is conceptualized in terms of the sensorimotor experience of catching a physical entity.

Our subjective experiences and judgments, like "one's self-esteem" or "a shiver" are relatively complex, abstract and unfamiliar to us. Using experience of our own body to conceptualize and reason about them makes them easier to understand. Human body metaphors of such kind are pervasive in English language, and serves as important cognitive approach to those abstract subjective experiences. If not interpreted metaphorically, concepts of subjective experiences and judgments will be senseless and "impoverished" (Lakoff \& Johnson, 1999, p. 61). It can be said that human body metaphor justifies the existence of the metaphorical usage of English body-action verbs.

To sum up, the conventionalized metaphorical usage of English body-action verbs indicates that human body metaphor is a vital cognitive approach to our subjective experiences and judgments. This is also in line with the metaphorical nature of thought principle. Based on the above analysis, it can be concluded that the metaphorical usage of English body-action verbs arises from our embodied experience. Due to the limitations of human cognition, we experience and understand one cognitive domain in terms of another. Concepts related to human, as the most familiar concepts to us and topping the unconscious "Great Chain of Beings" in human mind, are preferred to be the source domain in such cross-domain conceptual mapping. It is based on human's experience with their own body that human body metaphor becomes a possible cognitive approach to abstract and complex concepts of subjective experiences and judgments. The metaphorical usage of English body-action verbs does not directly result from the external reality. Instead, it comes from the embodied experience of the mind.

\section{CONCLUSION}

Metaphorical usage of English body-action verbs, mostly conventionalized, can reflect the essence of human cognition. This paper analyzed the cognitive motivation of predicative metaphor of three types of English body-action verbs. It was revealed that concepts related to human body, in most cases, are chosen preferentially as the source domain for cross-domain conceptual mapping. Based on human's experience with their own body and with a pervasive cognitive approach of human body metaphor in human mind, English body-action verbs are metaphorically applied to other abstract conceptual domains. The metaphorical usage of English body-action verbs comes from the embodied experience. In a broader sense, this research means a further step to explore predicative metaphor.

\section{ACKNOWLEDGEMENTS}

This study is supported by "the Fundamental Research Funds for the Central Universities" (Project No: SWU1609303).

\section{REFERENCES}

[1] Cameron, L. (1999). Operationalising "metaphor" for applied linguistics research. In L. Cameron \& G. Low (eds.). Researching and Applying Metaphor. Cambridge: Cambridge University Press, 328.

[2] Croft, W. \& D. A. Cruse. (2004). Cognitive Linguistics. Cambridge: Cambridge University Press.

[3] Crowther, J. (2015). Oxford Collocations Dictionary (2nd edition). Beijing: Foreign Language Teaching and Research Press.

[4] Gao, Q. \& Qin, X.G. (2009). The Conceptual Metaphors of Concrete Verbs in Food Category. Journal of Guangxi Normal University, 3, 84-89.

[5] Ge, J. M. \& F. F., Zhao. (2010). On Conceptual Metaphors of Motion Verbs and Their Mechanism. Foreign Language Research, 3, 43-46.

[6] Goatly, A. (1997). The Language of Metaphors: Literal Metaphorical. London: Routledge.

[7] Hornby, A. S. (2009). Oxford Advanced Learner's English-Chinese Dictionary (7th edition). Beijing: Commercial Press.

[8] Hu, C. Y. \& Y. T. Xu. (2020). A corpus-based study of market metaphor in Chinese and English economic media discourse. Foreign Language Research, 1, 42-48.

[9] Kittay, E. (1987). Metaphor: Its Cognitive Force and Linguistic Structure. New York: Oxford University Press. 
[10] Lakoff, G. \& M. Johnson. (1980). Metaphors We Live By. Chicago: University of Chicago Press.

[11] Lakoff, G. \& M. Johnson. (1999). Philosophy in the Flesh: The Embodied Mind and its Challenge to Western Thought. New York: Basic Books.

[12] Lakoff, G. \& M. Turner. (1989). More than Cool Reason: A Field Guide to Poetic Metaphor. Chicago: University of Chicago Press.

[13] Peng, Y. H. (2010). Studies on the metaphor mapping of verb. Foreign Language Research, 6, 37-40.

[14] Peng, Y. H. \& Y. Lv, (2015).Study on the metaphorical mechanism of verb with thinking activity meaning. Contemporary Foreign Language Studies. 11, 18-23.

[15] Su D. F. (2000). On the cognitive, psychological and linguistic causes for the emergence of metaphor. Foreign Language Research, 2, 23-33.

[16] Su Y.L. (2017). A review of multi-disciplinary studies on predicative metaphor. Modern Foreign Languages, 40 (5), $705-714$.

[17] Torreano, L. A., C. Cacciari \& S. Glucksberg. (2005). When dogs can fly: Level of abstraction as a cue to metaphorical use of verbs. Metaphor and Symbol, 20 (4), 259-274.

[18] Wang B., Z. R. Li, L.M. Wu.\& J. J. Zhang. (2019). Effects of embodied simulation on understanding Chinese body action verbs. Acta Psychologica Sinica, 51 (12), 1291-1305.

[19] Wang Y. (2002). The philosophical basis for cognitive linguistics: Embodied philosophy. Foreign Language Teaching and Research, 2, 82-89.

[20] Wilson, N. L. \& R. W. Gibbs. (2007). Real and imagined body movement primes metaphor comprehension. Cognitive Science, 31, 721-731.

[21] Yang, X. Y. \& B. X. Huang. (2000). A tentative study of English verb metaphor. Journal of Jishou University, 4, 82-84.

[22] Zhang, J. L. \& J. W. Zhu. (2011). Ontological study of verb metaphor. Foreign Language Education, 32 (1), 1-5.

Mingjie Huo was born in Henan Province, China. He received his MA in linguistics and literature from Henan University, China. $\mathrm{He}$ is currently a Ph.D. candidate in the College of International Studies, Southwest University, Chongqing, China. And he is a teacher in School of Foreign Studies, Guangzhou University, Guangzhou, China. His research interests include Cognitive Linguistics and pragmatics.

Jiaxuan Chen was born in Guangdong Province, China. She is currently a student in School of Foreign Studies, Guangzhou University, Guangzhou, China. 